Article

\title{
Gender, Fitness Doping and the Genetic Max. The Ambivalent Construction of Muscular Masculinities in an Online Community
}

\author{
Jesper Andreasson ${ }^{1, *}$ and Thomas Johansson ${ }^{2}$ \\ 1 Department of Sport Science, Linnaeus University, SE-391 82 Kalmar, Sweden \\ 2 Department of Education, Communication and Learning, University of Gothenburg, Box 300, \\ 40530 Gothenburg, Sweden; thomas.johansson@ped.gu.se \\ * Correspondence: Jesper.andreasson@lnu.se; Tel.: +46-480-446-091 \\ Academic Editor: Martin J. Bull \\ Received: 22 December 2015; Accepted: 26 February 2016; Published: 1 March 2016
}

\begin{abstract}
This article is based on written accounts posted on an online forum called Flashback. The purpose of the study was to explore how participants in this community negotiated the meanings of fitness doping and how such negotiations could be understood in terms of masculinity. The findings indicate that the Internet community studied in this article can be read as an example of a transformational process in which ordinary rules are questioned and partly put out of play. In the world of the bodybuilder, the marginal masculinity is, in certain senses, dominant. On the one hand, achieving a muscular and well-trained body is regarded as a core aspect of manhood within the community. Marginal masculinity is thus momentarily transformed into dominant and hegemonic masculinity. On the other hand, however, the findings also indicate that a drug-using, muscular masculinity is constructed in negotiation with other central masculine ideals, such as the employable man and the responsible father. Found within the community is a complex and dynamic interplay between intersecting discourses of manhood.
\end{abstract}

Keywords: online communities; fitness doping; illicit drug use; bodybuilding; masculinity

\section{Introduction}

In different sporting venues, the notion of masculinity has followed the imagery of athleticism like a cultural ally for centuries [1-4]. Through the imitation of physically demanding practices performed by older men and idols, young men have been said to internalize normative masculine values, through sport. In addition, devoting time to strengthening the body, building muscles and projecting an attitude of domination has historically been related to violence, warfare and the building of nations, thus implying an interest in cultivating what Mosse [4] describes as "the masculine stereotype". The cultural history of contemporary gym and fitness culture makes no exception from this kind of cultural narrative [5,6]. Klein [7], for example, who conducted one of the first bodybuilding studies in the early 1990s, describes bodybuilding as a predominantly masculine preoccupation. He also describes homophobia, hyper-masculinity and the use of illicit drugs, such as anabolic androgenic steroids (AAS), as institutionalized phenomena in this kind of physical culture (see also [8-10]).

In this article we will discuss the relationship between gender and fitness doping as it is negotiated within a specific online community. As a means of stressing the difference between doping in elite sport and doping in a fitness context (fitness doping), terms such as vanity doping or image-enhancing drugs sometimes have been employed [11]. Although members of this community predominantly appears to be frequenters of gyms, focused on muscle building practices, rather than members of sport teams, we have, however, chosen to use the term performance-enhancing substances (PES) exclusively. 
Motivated by the rationale that illicit drug use for image enhancing purposes also can be viewed as an activity performed to enhance for example a masculine identity, we argue that PES is a sufficient term for our analysis on fitness doping.

Directing our attention to the complex relationship between PES use and gender, one common position, in the literature, is that the main trigger for its use is men's desire to gain muscle mass and to construct a masculine identity [12-17]. Looking at previous research on gender and PES use one can see that the use also has been understood as an outcome of a search for a competitive edge within sport, as risk-taking, as an integral feature of hegemonic masculinity, and thus as an expression of some kind of societal over conformity when it comes to the construction of masculinity [18-21]. At the same time, however, the use has also been analyzed in terms of deviance and marginalization. It has been connected to mixed abuse, crime, violence and the margins of society [22,23]. Existing images of PES users are often quite judgmental, and the use has also been understood as an expression of a marginalized, uncertain and outdated masculinity [7,24].

Internationally, official regimes and public health organizations conduct fairly comprehensive anti-doping measures. As a consequence, numerous "new" ways to learn about and access PES have emerged. This is not the least the case in Sweden where legislation does not simply forbid the possession and distribution of for example AAS-like for example many other European countries-but also the presence of these substances in the body [11]. This development combined with technological development in recent decades has resulted in the emergence of new ways of accessing and discussing PES. Social media and different Internet forums, for example, have become part of a new self-help culture in which people can anonymously approach these substances, discuss their experiences of using them, and minimize the possibility of encounters with the police [25]. What we see today is the development of new PES use trajectories that sanction acceptable and unacceptable masculinities. As expressed by Monaghan [20], there is a gap between PES users' actions and societal expectations. Within this gap we will suggest that it is possible for users to renegotiate their practice in relation to possible health warnings, legal sanctions, and of course in terms of gender, as they formulate a rationale for their practice. One term often used when analyzing PES, body ideals, masculinity and muscular development is the "genetic max". We will further explore this concept and understanding of bodies, muscles and masculinity in the results. Furthermore, in this article we will focus exclusively upon the relation between PES and the construction of masculinity, although we are aware of that female bodybuilders also use PES and are involved in similar bodily endeavors as men [26].

In this article, we will focus on this emerging complexity in the understanding of illicit PES use and gender. Empirically we will focus on PES users narratives found on a Swedish online community. The purpose of the study is twofold. First, we aim to explore how participants in an online community named Flashback learn about and negotiate the meanings of PES use in the community and how such negotiations can be understood in terms of gender and masculinity. Second, we are interested in exploring how fitness practices, PES use and online fitness communities challenge dominant regimes of masculinity and gender equality. The aims of the article will be addressed using the following research questions:

RQ 1: What kinds of understandings of PES use are manifested in the online community and how is the practice related to Swedish legislation and official government policy?

RQ 2: What kinds of body ideals and symbolic language regarding drug use are developed within the community?

RQ 3: In what ways is PES use presented in terms of masculinity within the community?

\section{Theoretical Framework}

In this article, we will explore the dynamic interplay between "accepted" and legitimate identities and alternative or even "deviant" identities in terms of hegemonic and marginalized masculinity. Connell's [27] understanding of marginalization situates and positions masculinities within a gender theory framework configured by hegemonic masculinity. Thus, marginalized masculinities are 
often referred to as "outcasts", or as Cheng ([28], p. 295) expresses it, as those men who have a "disadvantaged unequal membership". Thus, in many ways, marginalized masculinities are located in relation to a middle masculinity that holds a cultural privilege. Dahl-Michelson and Nyheim [29] develops the notion of marginalized masculinities as not only those that could not meet hegemonic standards, but also did not operate or make sense of their identities through hegemonic gender norms see also [30]. In contemporary Western societies, a hegemonic masculinity would, for example, mean involved, communicative, gender equal, and well-trained but not huge or too muscular. As we see, there is a dynamic interplay between dominant ideals of masculinity in society at large, and more specific and subcultural ideals nurtured in certain social and cultural contexts. Bodybuilding culture may, for example, foster protest masculinity; that is, a marginal masculinity involving anti-social activities. Another way of looking at this could be to use the concept of hyper-masculinity, which can be described as a strong exaggeration of certain stereotypical male connoted qualities, such the emphasis on muscular strength, aggression, sexual virility and the subordination of women [31,32]. At the same time, within the subculture, these identities can in fact be combined with a desire to fit into the dominant masculinity [33]. Analytically, we will focus on the dynamic and complex interplay between, on the one hand, hyper-masculinity and marginalization, and on the other, hegemonic masculinity. In addition, we will also discuss the role of digital media when it comes to shaping and questioning the experience of marginalization.

We will use the concept of subculture in order to investigate how particular masculinities are created through social interaction within the online community. We will look closer at the interplay between subcultures and the mainstreaming of certain body ideals and practices. According to Fornäs ([34], p. 112):

One problem with earlier subcultural studies was their exclusive focus on homologies, on the ways in which subcultural styles fitted together into homogeneous totalities. This has to be counteracted by an attendance to the inner differences, tensions and contradictions within subcultures and groups, which newer studies of social relations show as an increasingly important element in late modern lifestyles and life forms.

Becoming a member of and joining an online community, for example, involves aspects of both identity construction and learning [35]. We suggest that such a process of learning also affects the individuals' identity and maybe more specifically the notion of masculinity being idealized $[6,25,36,37]$. As individuals gain knowledge and discuss theories about how to reach desired goals, they increasingly become integrated in the community. As a consequence, some people will then choose to take drugs, thus challenging the dominant norms and values in mainstream society, and at the same creating their own spaces of alterity. Analyzing an online community can thus give insight into the ways in which a particular subculture can create a space in which members simultaneously can feel elevated and marginalized. Following the discussion of subcultures as contradictory and ambivalent social constructions, we will also look deeper into how the PES user's perceptions of themselves adhere to different and sometimes even conflicting gender ideals.

\section{Research Design and Methodology}

This article is based on analysis of written accounts presented on an online Internet-based community [38]. We have sampled discussions posted on an online forum and community called Flashback. This virtual platform is hosted in Sweden and, although there are the occasional contributions posted in Norwegian, Danish and English, the postings are mainly in Swedish. On Flashback one can read that this is "Sweden's largest forum for freedom of expression, opinion, and independent thinking" [39], and it may therefore be considered a highly open-minded forum as regards prohibited activities such as the use of PES [25]. On Flashback anyone with an Internet connection can read different postings and learn from other community members' experiences. A person can also create an account and with a fictive user name start up different threads and 
discussions with other members. Discussions basically concern just about anything, such as sport, sex, home, culture, travel and more. However, due to the fact that the forum facilitates the expression of opinions anonymously, many discussions concern prohibited activities. One popular category on Flashback is drugs, with PES representing as a subcategory.

Although the use of usernames precludes the confirmation of gender and other kinds of demographic information about community members, the postings analyzed are apparently dominated by men [40]. As stated earlier, in previous research the use of PES has also been considered a highly gendered activity. Analyzing postings on Flashback gives us not only access to different discussions on PES, it also enables us to analyze how this practice is understood and negotiated in terms of masculinity within the community. When conducting our online research we have been inspired by Kozinets [38] who developed a specifically designed method for studying different online forums and communities, "netnography". Our analytic focus is on different text extracts published on Flashback, taking the perspective that these extracts and the ensuing discussions can be viewed as cultural manifestations through which the understanding of a particular activity is constantly negotiated [38,41].

In our sampling of postings, we focused on the contents of two main themes connected with discussions on PES. The first theme was named "Doping substances" and the second "Course reports", and this theme contains extensive discussions about the actual use and procedures involved in the use of PES. At the time of analysis, these themes consisted of 107 and 1741 threads (sub themed discussions), respectively - threads in which understandings of different kinds of PES where negotiated and reports on personal courses recited. As suggested by Kozinets ([38], p. 95), data collection in netnography does not happen in isolation from data analysis. In our analysis, we have tried to understand the reasoning of community members, and to read different postings from the perspective that they are rich sources of cultural information. Our sampling of postings and discussions have then been distinguished by an intertwining of relevance to the research questions, and the richness, heterogeneity and interactivity manifested among participants as they engaged in different discussions within the community. Put differently: In the selection of quotes, we have aimed to capture narratives in which PES use is discussed dynamically within this community and how these discussions can be understood both in terms of dominant and marginalized conceptions of masculinity.

Although community members on Flashback can use fictive usernames, and most likely are aware that their postings will be stored and transmitted, some aspects of this study call for an extended ethical concern [42]. This article focuses on postings in which community members discuss and sometimes promote a criminalized activity. This means that the quotations we have chosen for our analysis could have legal repercussions, if the authorities were to locate the particular IP address of a community member. Furthermore, there is little information given in the postings regarding the age of the community members, implying that we cannot say with certainty whether they are minors or adults.

To protect the identity of the community members we took the following measures. First, we created fictitious usernames for all of the participants quoted. Second, we translated the postings, which are originally in Swedish into English, making it more difficult to use available search engine technology in order to track down specific postings and community members. Third, in our sampling of postings we were careful not to focus on particularly sensitive information. This means that information of a personal character, such as the mentioning of a specific gym, a person or the home town of a community member, has been left out. Accordingly, we restricted our use of quotations to those that could properly answer the research questions see [43].

\section{Findings}

This section is organized according to the research questions of the article. First we will explain how PES use is discussed on flashback trying to present the kind of community being the unit of analysis and also situating the community in relation to for example current legislation and popular perceptions on drug use in Swedish society. Consequently, we will here present the texture of the 
community, discussing it in terms of how a marginal position is gradually embraced and legitimized. Then we will zoom in on the practice and the kind of symbolic language that is developed within the community and connected to the practice. Finally we will analyze how the drug use practice is understood and negotiated in terms of different notions of masculinity and how idealized masculinities, when re-contextualized, are seen as marginal and vice versa. Following this line of thought and structure we will we suggest that it also becomes possible to examine how the drug use practice is related to dominant regimes of masculinity and ideals of gender equality within mainstream Swedish society.

\section{1. (Re)Negotiating PES}

The subject of the pros and cons of PES use is popular on Flashback and attracts lively debate. These kinds of discussions are highly relevant for many reasons. First, they are important if we want to understand how different members negotiate and understand the use of PES. Second, such an understanding could clarify the different ways in which different members relate to PES and how dominant perspectives on PES use are formed and, sometimes, challenged within the community. Third, they constitute significant data that could be analyzed in relation to Swedish legislation and official state policy.

The section on Flashback entitled "Course reports" contains extensive discussions about PES. Often these discussions are initiated by a seeming novice who expresses a desire to learn more about the practice. In one posting, for example, a member explains that he has been doing strength training for a while and is thinking about starting a course of steroids in order to further boost his muscular development. He is a little hesitant, however, regarding the possible side effects. He reaches out for some advice on what to do, and gets the following answer:

Let me tell you, I was in your situation when I was about 18 years old. I never had a drink, I trained seriously without using steroids and I followed a healthy diet, but I wanted to get results faster. I did not want to wait. But I waited anyway. For one year I waited and built a better foundation to start with. So now I have been on steroids since I was 19, and today I am 20 years old. It is the best thing I've ever done. During this year I have grown enormously-I've gained at least $10 \mathrm{~kg}$ of muscle mass. About my decision to start using at the young age of 19? Well, actually I'm really happy with it, and I feel 100 times better than before. I look forward to every new day. But also, if you want to start using, only do it if you can accept that there may be side effects and be aware that it's easy to get stuck, never wanting to get off the juice again (WaitOrNot).

WaitOrNot quickly adopts the role of the experienced user. He also describes his personal process of deciding to engage in drug use. In addition, he presents a complete chart of his own courses of steroids and lets readers know what to do and expect, and how to avoid potential side-effects. In the same thread, several other community members describe their similar PES use trajectories. Altogether, these postings articulate a process of learning about the practice and a way to understand it. Information is distributed and testimonies given. Different variables, such as age, strength training history, drug experience, health, body building goals, and possible side-effects, are integrated in the narratives. Consequently, altogether this information represents quite a comprehensive platform that new members can take advantage of when deciding whether to engage in PES use. What we also have here is narratives by young men (novices), to some extent feeling physically marginal to the cultural hegemonic ideal, seeking ways to become part of it. Sought for is a key to transition from the marginal to the hegemonic body ideal, although through illegal means. Many of the Flashback postings are also definitely encouraging when discussing the ways to complete such a transition. However, there are also critical and dissuasive opinions, such as the following.

There are plenty of negative aspects of steroids that people do not seem so eager to talk about openly. As it is, I really believe that you should not start with steroids when you're, like, 18 or 20. This is a decision that has to mature over time. You have to mature both 
physically and mentally. A teenager is not mature! I will always argue for this statement. One of my best friends is an old bodybuilding profile today. He started using steroids when he was 16 . Today, at nearly 30 , his system is totally fucked up. He gets problems with asthma and other things when he is off the steroids. He only gets horny at odd times, and more. He really regrets that he started so early (NoSteroids).

Community members do not always agree with one another, and when it comes to the use of PES many different positions are explored and developed. At the same time, the dominant attitude toward PES, as expressed on Flashback, appears to be clearly encouraging, or at least cautiously favorable. As a consequence, when NoSteroids posts his critical view of PES use, other members are quick to counter this narrative, formulating vocabularies of motive and trying to legitimize the practice [20]. For example, some postings dismiss him, describing his bodybuilding friend with problems as a person who probably started without knowing what he was doing, and is therefore an uninformed and ignorant user. Others talk about health and the importance of using lower dosages and taking longer breaks between courses. This is clearly an issue that community members find relevant. While potential health risks associated with the practice are acknowledged, they are also presented adjacent to advice regarding how to recognize and deal with them. What is taking place here is a critical discussion and social diffusion of knowledge regarding PES use. Furthermore, through this socially constituted process within the community the marginal position, the experience of being a man who uses PES in order to build muscles is legitimized and somewhat also idolized. Knowledge on PES use then becomes a resource within the community through which a marginal position is questioned.

In the postings, members discuss PES and analyze different kinds of substances in terms of bodily expectations and possible side-effects. These discussions can thus be understood as part of an ethno-pharmacological culture through which the instrumental use of PES is partly normalized and rationalized within the community $[19,44]$. Some members are also, as above, more eager than others to discuss occurring side-effects with their use. Side-effects such "bitch tits" (gynecomastia) and acne are, for example, mentioned in these discussion [45]. Research also show that the use of PES is associated with mild to major side-effects depending on dosages [23,46], which of course further motivates community members to get informed on possible ways to avoid this. Saltman [47] has in a similar way discussed how both female and male bodybuilders are pushing femininity and masculinity, respectively, to their limits with the help of PES, and in doing so simultaneously maintain and undermine gender norms. In this sense, the development of gynecomastia, for example, could be read as an example of how the male bodybuilder's body parodies its own hyperbolic butchness as it transforms into the feminine ([47], p. 50).

Through the different threads members can read and learn from each other. The knowledge being shared is also presented in association with a medical discourse. In developing their arguments and theories about how to best use the drugs, the community members do not focus on the ethical aspects of this use, but instead on how different substances affect the body. In this way, the understanding of the practice is constructed as if it belongs, at least partly, to a health-promoting agenda, and is thus quite the opposite of official Swedish policy, which is often described as having a less knowledgeable foundation. This is obvious in the quotation below in which one community member tries to explain his views on Swedish legislation against PES and government policy.

Regarding doping substances, I think that Swedish government policy is idiotic. Certainly it is true that many people commit violent crimes due to the use of steroids, but on the other hand there are also many who manage their bodybuilding hobby in an exemplary fashion. Doping should clearly be legal (I'm talking about hobby doping; obviously I don't defend cheating in competitions). The doping ban is a consequence of the government's feministic hatred of men. Smash the state! (Legalise).

Certainly there is not much of identification with a political agenda of gender equality built into this posting. Instead the use of PES is understood as a viable path to secure manhood, and a way to 
construct a hyper-masculine body. Above, the understanding of the practice is detached from how it may be used in organized sport in order to cheat, and is instead connected to a more neo-liberal, individualistic ideology. In addition, in many postings the right to choose what to do with your own body is asserted as a rationale for the practice. This rationale is thus formulated in relation to perceived changes in society and to the meanings of manhood and a gender-equal society. What we are witnessing here is the construction of an alternative understanding of masculinity and a response to the experience of being condemned by (feminist) representatives of mainstream society [48].

Clearly there is an awareness of the risks attached to PES use being expressed within the community. The choice of using PES is constantly being negotiated by different members; in these discussions different positions are adopted as regards the understanding of the practice. For some members it seems to be mainly understood as possible way to boost a muscular masculinity, while others are more careful in their approach, trying to problematize the practice in relation to age, maturity, goals, risks, health and more. One thing clearly being negotiated by different members within the community is also how the practice can be understood in terms of body ideals, gender and masculinity. This will be further developed in the two following sections.

\subsection{PES and the Genetic Max}

Like many other communities, Flashback can be understood as part of a culture with its own ways of talking about and understanding particular activities. Using different illicit substances while building up a solid body can thus be understood as the construction of a subcultural affiliation in which a symbolic language game and specific terminology are developed. One term often used when discussing PES, body ideals and muscular development is the "genetic max".

Certainly it is reasonable to assume that we all have a genetic max, but the problem is to determine what that max is, for each individual. We all have different preconditions. If we look at testosterone production, for example: it varies quite a lot between different individuals. Then, in addition to the testo, there are hell of a lot of other factors that will affect how easily you can gain muscles (thyroid hormones, growth hormones, insulin). Your age is also a factor. It must be really hard to tell if someone reached their genetic max, when there are so many factors. One can always try a change something when it comes to training, nutrition, rest, etc. (WhatIsMax).

The relationship between PES use and the genetic max is complicated. Sometimes the term genetic max is understood as a means to reach bodily goals that exceed a person's genetic max, and sometimes it is more about using PES in order to reach the max [25]. The conceptual discussions about the genetic max can therefore be understood as a mixture of conceptions of physical potential and masculine fantasies, sometimes dramatic, about what is humanly possible to achieve [8]. This becomes evident in the posting below in which a member describes the expectations he had on his first course of steroids:

"No Guts, No Glory".

Mission accomplished! It's time to get real! Be great or be nothing! I am so fucking powered up now. It will surely be interesting to see how things turn out at the gym. While working out clean, I have already managed to increase the number of reps on some exercises, despite my diet, so there will probably be like a swelling explosion with the juice [PES] in my system! (FirstInjection).

Clearly, PES is understood here as a symbol of a rite of passage [49], enhancing different features of masculinity. The expectations of bodily possibilities "with juice in the system" are high. Most often discussions like above also are connected to ideas about reaching one's genetic max, being transformed into a new and better self, and becoming more of a man. Furthermore, when it comes to postings regarding the possible ways to achieve one's genetic max without using PES, the views are quite pessimistic. This becomes evident in the posting below where a community member explains what he thinks of "natty" (natural) bodybuilding. 
All these "natty" bodybuilders have given people a distorted image of what is possible to achieve in a natural way. Natural bodybuilding is just something shitty that the industry created in order to sell us a bunch of crap. "Oh look, he is natural". "If I only buy the same protein drinks as him, and follow the advice he presents in his blog, then I can also be like him!" The truth is that steroids are used on the "natural" bodybuilding scene. Another thing: I don't understand the logic of those who are constantly saying "I think he is clean just because his physique can be reached by natural means." ( . . ) It's also worth checking out the time it takes for all these "natties" to reach their maximum natural potential. It doesn't take two to three years to reach one's genetic max; it takes a fucking lifetime, and in the meantime, you have to have experience and knowledge (NoNatties).

On Flashback there are quite a few postings in which the use of PES is rationalized in different ways. PES is obviously an intrinsic part of this online culture: there are even members who discuss ways to use PES in order to change the basic conditions of the human body, to exceed the limits of human genes and reach the genetic max. In this sense, we are witnessing the construction of a transformable masculinity and the development of strong ideas about scientifically engineered "super-bodies" (see also [50,51]). The skeptical perspective put forward regarding the chances of getting results from natural bodybuilding also strengthens this kind of narrative. The natural bodybuilder is seen as more or less a moral fantasy—a "fitness cream puff" who sells useless products for financial gain.

\subsection{Doing Manhood and Masculinities}

From the different postings on Flashback, it is obvious that the (anticipated) effects of PES are largely connected to the notion of masculinity. Below, one community member explicitly tries to situate his PES use in relation to manhood, career and sexual virility.

I have experienced really good effects. I have become extremely focused-more of a man. At work, yeah, when I talk, people shut up and show respect. Since my goal in life is to dope myself as much as possible, to achieve as much as possible, I have always seen my job as a parenthetical detail—something you just have to do until you arrive at your real job, the gym. So I've never really invested in pursuing a career. But still, I speak more in front of people. I have become more sincere and upright. I give and take more ( . . ) not to mention the insane sex drive you get on testo-makes women think you are from Planet Porno (HeMan).

The above posting vividly captures and understanding of PES that involves an anticipated process of transformation. The PES use is basically connected to adjectives describing the self as becoming more of something, such as "focused", "muscular" and "virile". Other posters describe how they have developed greater interest in furthering their education, performing at the top of their class in university, and more. Despite the occasional mention of other, negative consequences, these qualities are basically described as being desired. They are connected to the construction of a dominant, muscular and self-assured (hyper) masculinity. It is a rational and performance-oriented masculinity that emerges in the postings. This masculine position is further developed below, where a community member constructs a hypothetical experiment, while simultaneously trying to develop his ideas on the limit-pushing potential of PES.

Think about this: Wouldn't it be fun to conduct this experiment. Joe works as an officer and his brother works at Lindex [Swedish women's lingerie chain], selling women's underwear. You sneak some oestrogen into Joe's coffee and give his brother testo instead. You do this for a couple of months. Talk about different results! What do you think would happen? Yeah, I think I know. In this way we would play out the extremes against each other, to see what really happens, within a particular profession. Testo could be EXTREMELY beneficial. 
Ha, ha, yeah, and it would be fun to see the outcome. The total ruin! From officer to army bitch! Ha, ha. I guess that the other military boys wouldn't have to pay for porn mags any more. And the brother would probably be reported for sexual harassment at Lindex, found by the surveillance monitors jerking off, while watching the women trying on lingerie in the changing rooms (TheProfessor).

Obviously, PES is connected to an expected transformation and construction of masculinity. Although not all of the features that result are desired, the outcomes of PES use clearly relate to a masculine and heterosexual stereotype. Aggressiveness and dominance (or the lack thereof), sexual virility and callous sexual attitudes toward women are constructed as part of a hyper-masculine identity, fuelled with testosterone. The imagery of masculinity emerging in this narrative is thus not constructed in alliance with gender equality and the concept of the communicative, emphatic and involved father and man for example. However, while many of the postings seem to rationalize PES use, constructing it as a masculinity booster or anchor, there are also narratives in which its use is understood as an activity that put aspects of manhood at risk. This is exemplified in the posting below.

I actually think it's hard to get anywhere in your career, if we're talking about more qualified jobs. If I were an employer I would probably hesitate before employing a guy who was too big and had obvious side-effects of steroids. Imagine that nice office, and a guy who just wears GASP clothing, as regular shirts don't fit. Hmmm. After all, my experience from different workplaces is that there's a lot of bullshit said behind the backs of people who look like they're doped (TheEmployer).

In the posting above, the use of PES is understood in quite a pessimistic way when related to career advancement. It exemplifies the negotiation between a muscular and dominant hyper-masculinity and what are perceived to be other important aspects of manhood. The doped body, that is the dominant and intimidating body, is here seen as something of threat to employability and the imagery of the breadwinner. Although PES use is mainly discussed in positive terms on Flashback, it is not always understood as a winning concept. Clearly the understanding of the practice is situated and somehow shifting. This becomes abundantly clear below, where a young single dad, after asking for advice regarding the risk of losing custody if he were to be caught by the police, tries to explain his perspective on life, drugs and fatherhood.

The thing is that I didn't seek out family life. I thought that I would be with my girlfriend for life, that we would get our education and live the life of a child-free couple. Then came the news that she was pregnant, and she wanted to keep it, and my whole world collapsed. I played along for a year. After two years I began to question my life situation on a daily basis. Then I left my family after 2.5 years. Now, I want to start a new life. The plan is to move, get a degree, focus on my training and start a course of steroids. Basically, I want to do what I want, before I start a family (I was 22 when I became a father). Am I selfish leaving my child? Yes, but what about mothers who give birth to a child against the man's will and think it's going to work (DaddyNo).

The above posting attracted a lot of interest. DaddyNo did not, however, get many comments about custody issues as he had initially hoped. Instead, several members condemned DaddysNo's line of reasoning. To be clear: the discussion on Flashback is mainly encouraging when it comes to PES use, but this is obviously not the case when the use is situated as in DaddyNo's story. Instead, DaddyNo was strongly advised not to use drugs. Several community members become clearly irritated, calling him "immature" and "self-centred"- "an idiot with no character". He is instructed to rethink his priorities in life and to take responsibility for his actions. One community member summarizes the advice contained in the thread by saying: "Be a man and take care of your child. I know what it means to grow up without a father and I would never expose my own child to that." Clearly, there are different notions of masculinity being juggled in this discussion of PES and PES use. The masculine 
body, the dominant man, the employee, the breadwinner, and particularly, the responsible and mature father are all integrated in the negotiation of manhood and steroids. The masculinities constructed in the postings are thus understood slightly differently, depending on situation and how the (potential) PES use is contextualized by the community members.

\section{Conclusions}

The Internet community studied in this article exemplify a transformational process, through which ordinary rules and regulations are questioned and partly put out of play. What is studied here is a process of de-regulation and de-normalization, in which the notion of masculinity and the acceptance of certain forms of drug use is extended and expanded considerably. This process of normalization and acceptance of drug use within the community is constructed in alliance with neo-liberal attitudes and the cult of the individual, making it possible to transgress and challenge norms and regulations [52,53]. These processes are, of course, also connected to a more general discussion of how neo-liberal discourses have penetrated our way of thinking about individual freedom and health [54]. In some ways, the striving for the perfect body even makes it logically necessary, for instance, to challenge legislation on PES and to develop subcultural norms and values. And in the Internet community studied in this article, people can find extensive knowledge about and substantial support for the necessity of using certain means, and certain illicit drugs, to achieve their goals [25].

In the different postings we can see how different body ideals and notions of masculinity are pitted against each other, and how a marginalized masculinity and identity in the subcultural context is sometimes regarded as a dominant and hegemonic ideal. In some postings it also appears obvious how pride in one's physical transformation, the attainment of an idealized masculinity and the symbolically loaded language expressing high expectations can rapidly turn into something perceived as shameful behavior, when the circumstances are laid out in a problematic way [55]. The notion of masculinity attached to the understanding of PES use, as it is expressed here within the community, should be understood as a scattered and uncertain construction. Within the community it is most evoked to counter and challenge reductive representations put forward by Swedish official policy and media, for example [56]. This form of protest masculinity, however, is not always idealized within the community. Masculinity here is, for example, constructed in the intersection between a muscular masculinity and ideas about the employable man and the responsible father. When one member expresses a desire to be an absent father and to simultaneously focus on training and muscle development with the help of PES, it is met with strong condemnation. Some community members apparently understand fatherhood and maturity as superior masculine ideals. Consequently, abdicating one's role as father and leaving an innocent child behind is not legitimate in the search for freedom and a muscular masculinity.

Many of the behaviors and bodily appearances constructed within this subculture could be regarded as signs of marginalization — of a marginal masculinity in society at large. However, what we find here is an interesting relationship between hegemonic and marginalized hyper-masculinities. In the world of the bodybuilder, the marginal masculinity in certain senses becomes dominant. In one sense, achieving a muscular and well-trained body is regarded as a core aspect of masculinity within the community. In another sense, however, the practice - the trajectory-leading to such a hyper-masculine body is also challenged by other highly valued masculine ideals. What makes this even more complex today is a trend towards the normalization of the hard-core muscle culture cultivated in the fitness and bodybuilding context, leading to changes in attitudes towards drugs, hyper-bodies and protest masculinity in society at large. To a certain extent, we are now seeing hyper-masculinity becoming normalized and brought into mainstream culture. If we look at the film industry and its celebration of muscular masculinity, this becomes obvious. Over time, bodybuilding culture has moved from being an extreme subculture to being integrated into the mainstream, feeding into contemporary masculine ideals and creating a new bodily ethos. 
Author Contributions: Jesper Andreasson has been responsible for the study. All the different steps in the research process has however been carried out in close and dialogical collaboration with Thomas Johansson. The paper is written by both authors.

Conflicts of Interest: The authors declare no conflict of interest.

\section{References}

1. Allen Guttmann. Women's Sports. A History. New York: Columbia University Press, 1991.

2. Michael Kimmel. Manhood in America. A Cultural History. New York: The Free Press, 1996.

3. Michael A. Messner. Power at Play. Sports and the Problem of Masculinity. Boston: Beacon Press, 1992.

4. George Lachmann Mosse. The Image of Man. The Creation of Modern Masculinity. New York and Oxford: Oxford University Press, 1996.

5. Michael Anton Budd. The Sculpture Machine. Physical Culture and Body Politics in the Age of Empire. London: MacMillan Press, 1997.

6. Bryan E. Denham. "Masculinities in hardcore bodybuilding." Men and Masculinities 11 (2008): $234-42$. [CrossRef]

7. Alan M. Klein. Little Big Men. Bodybuilding, Subculture and Gender Construction. New York: State University of New York Press, 1993.

8. Adam Locks, and Niall Richardson, eds. Critical Readings in Bodybuilding. New York: Routledge, 2012.

9. Shelly A. McGrath, and Ruth A. Chananie-Hill. “'Big Freaky-Looking Women'. Normalizing Gender Transgression through Bodybuilding." Sociology of Sport Journal 26 (2009): 235-54.

10. Roberta Sassatelli. Fitness Culture. Gyms and the Commercialisation of Discipline and Fun. Basingstoke: Palgrave MacMillan, 2010.

11. Ask Vest Christiansen. "Doping in Fitness and Strenght Training Environments. Politics, Motives and Masculinity." In Elite Sport, Doping and Public Health. Edited by Verner Moller, Mike McNamee and Paul Dimeo. Odense: University Press of Southern Denmark, 2009, pp. 99-118.

12. Paul Dimeo. A History of Drug Use in Sport 1876-1976. Beyond Good and Evil. London and New York: Routledge, 2007.

13. Andrew B. Parkinson, and Nick A. Evans. "Anabolic androgenic steroids. A survey of 500 users." Medicine and Science in Sport and Exercise 38 (2006): 644-51. [CrossRef] [PubMed]

14. Krzysztof Sas-Nowosielski. "The abuse of anabolic-androgenic steroids by Polish school-aged adolescents." Biology of Sport 23 (2006): 25-35.

15. Donald R. McCreary, and Doris K. Sasse. "An Exploration of the Drive for Muscularity in Adolescent Boys and Girls." Journal of American College Health 48 (2000): 297-304. [CrossRef] [PubMed]

16. Jesper Andreasson, and Thomas Johansson. The Global Gym. Gender, Health and Pedagogies. Houndmills: Palgrave Macmillan, 2014.

17. Lee Monaghan. Bodybuilders, Drugs and Risk. Health, Risk and Society. New York: Routledge, 2001.

18. Jesper Andreasson, and Thomas Johansson. "Between Beauty and Performance. Towards a sociological understanding of trajectories to drug use in a gym and bodybuilding context." Scandinavian Sport Studies Forum 4 (2013): 60-90.

19. Lee Monaghan. "Challenging medicine? Bodybuilding, drugs and risk." Sociology of Health $\mathcal{E}$ Illness 21 (1999): 707-34. [CrossRef]

20. Lee F. Monaghan. “Accounting for Illicit Steroid Use. Bodybuilders' Justifications." In Critical Readings in Bodybuilding. Edited by Adam Locks and Niall Richardson. New York: Routledge, 2012.

21. Nicole Thualagant. "The Conceptualization of Fitness Doping and its Limitations." Sport in Society: Cultures, Commerce, Media, Politics 15 (2012): 409-19.

22. Robert H. DuRant, Luis G. Escobedo, and Gregory W. Heath. “Anabolic-Steroid Use, Strength Training, and Multiple Drug Use among Adolescents in the United States." Pediatrics 96 (1995): 23-29. [CrossRef]

23. Vanessa Lentillon-Kaestner, and Frauke Ohl. "Can we measure accurately the prevalence of doping? " Scandinavian Journal of Medicine \& Science in Sport 21 (2011): 132-32. [CrossRef] [PubMed] 
24. Alice Riis Bach. Mænd och muskler. En bog om Stryketæning og Anabole Steroider [Men and Muscles. A Book about Weight Lifting and Anabolic Steroids]. Copenhagen: Tiderna skifter, 2005.

25. Jesper Andreasson, and Thomas Johansson. "Online Doping. The new self-help culture of ethnopharmacology." Sport in Society, 2015. [CrossRef]

26. Rebecca Ann Lock. "The Doping Ban. Compulsory Heterosexuality and Lesbophobia." International Review for the Sociology of Sport 38 (2003): 397-411. [CrossRef]

27. Robert William Connell. Masculinities. Cambridge: Polity Press, 1995.

28. Cliff Cheng. "Marginalized masculinities and hegemonic masculinity: An Introduction." Journal of Men's Studies 7 (1999): 295-315. [CrossRef]

29. Tone Dahl-Michelsen, and Kari Nyheim Solbrække. "When bodies matters: Significance of the body in gender constructions in physiotherapy education." Gender and Education 26 (2014): S672-87. [CrossRef]

30. Eric Anderson. Inclusive Masculinities: The Changing Nature of Masculinities. London: Routledge, 2009.

31. Donald L. Mosher, and Mark Sirkin. "Measuring a macho personality constellation." Journal of Research in Personality 18 (1984): 150-63. [CrossRef]

32. Jamison F. DeReef. “The Relationship between African Self-Consciousness, Cultural Misorientation, Hypermasculinity, and Rap Music Preference." Journal of African American Studies 9 (2006): 45-60.

33. Linda McDowell, Esther Rootham, and Abby Hardgrove. "Precarious work, protest masculinity and communal regulation: South Asian young men in Luton, UK." Work, Employment and Society 28 (2014): 847-64. [CrossRef]

34. Johan Fornäs. Cultural Theory \& Late Modernity. London: Sage, 1995.

35. Etienne Wenger. Communities of Practice. Cambridge \& New York: Cambridge University Press, 1998.

36. Howard S. Becker. "Becoming a Marihuana User." American Journal of Sociology 59 (1953): 235-42. [CrossRef]

37. Sherry Turkle. Life on Screen. Identity in the Age of the Internet. London: Weidenfield and Nicolson, 1995.

38. Robert V. Kozinets. Netnography. Doing Ethnographic Research Online. London: SAGE Publications, 2010.

39. Flashback (n.d) Flashback forum. Available online: https:/ / www.flashback.org/ (accessed on 1 March 2016).

40. Aaron C. T. Smith, and Bob Stewart. "Body perceptions and health behaviors in an online bodybuilding community." Qualitative Health Research 22 (2012): 971-85. [CrossRef] [PubMed]

41. David Porter. Internet Culture. New York: Routledge, 1997.

42. Joseph B. Walther. "Research Ethics in Internet-Enabled Research. Human Subjects Issues and Methodological Myopia." Ethics and Information Technology 4 (2002): 205-16. [CrossRef] [PubMed]

43. Robert C. Hsiung. "The best of both worlds. An online self-help group hosted by a mental health professional." Cyber Psychology \& Behavior 3 (2000): 935-50. [CrossRef]

44. Lee F. Monaghan. "Vocabularies of motive for illicit steroid use among bodybuilders." Social Science $\mathcal{E}$ Medicine 55 (2002): 695-708. [CrossRef]

45. Daryl Adair. "Steroids, Male Body Image, and the Intimate Self." In Embodied Masculinities in Global Sport. Edited by Jorge Knijnik and Daryl Adair. Morgantown: Fitness Information Technology, University of West Virginia Press, 2015.

46. Ivan Waddington, and Andy Smith. An Introduction to Drugs in Sport. Addicted to Winning? London and New York: Routledge, 2009.

47. Ken Saltman. "Men with Breasts." Journal of the Philosophy of Sport 25 (1998): 48-60. [CrossRef]

48. Gresham M. Sykes, and David Matza. "Techniques of Neutralization. A Theory of Delinquency." American Sociological Review 22 (1957): 664-70. [CrossRef]

49. Arnold Van Gennep. The Rites of Passage, 1st ed. London: Routledge, 2004.

50. Mikhail Mikhaŭlovich Bakhtin. Rabelais and His World. Bloomington: Indiana University Press, 1984.

51. Victoria Pitts. In the Flesh: The Cultural Politics of Body Modification. New York: Palgrave Macmillan, 2003.

52. Michel Foucault. Power. Essential Works of Foucault 1954-1984. Harmondworth: Penguin Books, 1994, vol. 3.

53. Peter Miller, and Nikolas Rose. Governing the Present. Administering Economic, Social and Personal Life. Cambridge: Polity Press, 2008.

54. Emma Rich, and John Evans. "Now I am NObody, see me for who I am. The paradox of performativity." Gender and Education 21 (2013): 1-16. [CrossRef] 
55. Andrew C. Sparkes, Joanne Batey, and Gareth J. Owen. "The Shame-Pride-Shame of the Muscled Self in Bodybuilding." In Critical Readings in Bodybuilding. Edited by Adam Locks and Niall Richardson. New York: Routledge, 2012.

56. Kevin Mogensen. Body Punk. En Afhandling om Mandlige Kropsbyggere og Kroppens Betydninger $i$ Lyset av Antidoping Kampagner [Body Punk. A Thesis on Male Bodybuilders and the Meanings of the Body in the Light of Anti-Doping Campaigns]. Roskilde: Roskilde Universitetscenter, 2011.

(C) 2016 by the authors; licensee MDPI, Basel, Switzerland. This article is an open access article distributed under the terms and conditions of the Creative Commons by Attribution (CC-BY) license (http://creativecommons.org/licenses/by/4.0/). 